\title{
РИМСКОЕ ВЛИЯНИЕ В КУЛЬТУРЕ ЭЛЛИНСКИХ ГОСУДАРСТВ СЕВЕРНОГО ПРИЧЕРНОМОРЬЯ В І-ІІ ВВ. Н.Э.
}

\section{ROMAN INFLUENCE IN THE CULTURE OF THE HELLENIC STATES \\ OF THE NORTHERN BLACK SEA REGION IN THE I-II CENTURIES AD \\ L. Tarasova \\ D. Didenko}

Summary: In this article, based on a comprehensive analysis of epigraphic, numismatic, pictorial and archaeological sources, various aspects of the influence of the Roman Empire on the culture of the Bosporan Kingdom, Chersonesos and Olbia in the I-II centuries AD are considered. The authors conclude that in the Hellenic states of the Northern Black Sea region, the cultural influence of Rome can be traced in coinage, architecture, sculptural portraiture and painting, forms of leisure (visiting baths, gladiatorial games and bestiaries), and in religious life - in the appearance of the cult of the Roman emperors.

Keywords: the Roman Empire, Northern Black Sea region, Bosporus Kingdom, Chersonesos, Olbia, cultural influence.

\author{
Тарасова Любовь Валерьевна \\ К.и.н., ФГБОУ ВО «Калужский государственный \\ университет им. К.Э. Циолковского» \\ tarlv@mail.ru \\ Диденко Дарья Александровна \\ ФГБОУ ВО «Калужский государственный \\ университет им. К.Э. Циолковского» \\ dashuta.didenko.1997@mail.ru
}

Аннотация: В данной статье на основе комплексного анализа эпиграфических, нумизматических, изобразительных и археологических источников рассматриваются различные аспекты проявления влияния Римской империи на культуру Боспорского царства, Херсонеса и Ольвии в I- II вв. н.э. Авторы приходят к выводу, что в эллинских государствах Северного Причерноморья культурное влияние Рима прослеживается в монетном деле, архитектуре, скульптурном портрете и живописи, формах проведения досуга (посещении терм, гладиаторских игр и бестиариев), а в религиозной жизни - в появлении культа римских императоров.

Ключевые слова: Римская империя, Северное Причерноморье, Боспорское царство, Херсонес, Ольвия, культурное влияние.

Веспасиана, Тита, Домициана, Траяна [1, с. 100; 5, с. 201; 23, с. 25], а также курульные кресла, венки, скипетры с бюстом императора и другие атрибуты власти, символизирующие получение права на трон боспорскими царями со стороны Рима [1, с. 154-157; 21, с. 120-124, 142; 23, с. 27]. Во-вторых, вес монет был приведен в соответствие с римским стандартом, например, на Боспоре золотые монеты, чеканившиеся с 9 года н.э., совпадали по весу с римским ауреусом. В-третьих, римское влияние, вероятно, проявилось и в материале монет. Например, сестерции и дупондии при Рескупориде I выпускали из аурихалка. Этот сплав поступал в Боспорский монетный двор из Римской империи, которая, как считают некоторые исследователи, в производстве аурихалка была монополистом и, следовательно, необходимо было получать разрешение римских властей на чеканку из него $[17$, с. 337, 341]. В Ольвии отмечается ориентация монетного двора на реальный вес средний вес римских монет [7, с. 24], хотя на городских монетах нет изображений или имен римских императоров или иных символов, демонстрирующих политическую зависимость от Римской империи [1, с. 58].

Римское влияние можно проследить в строительстве, особенно в фортификационных сооружениях первых веков новой эры. Так, планировка Илурата и Харакса очень похожа на римские укрепления; там применялись 
характерные сводчатые конструкции и арки [10, с. 145; 22 , с. 297; 23, с. 33 слл.]. В гражданском строительстве такое влияние менее заметно, но бросается в глаза некий прагматизм, который скорее свойственен римлянам, чем эллинам: первый этаж жилищ зачастую приспосабливается для хозяйственных нужд и производства, меньше становится украшений и ордерных элементов [10, с. 140]. Из принципиальных новшеств в строительном деле, появившихся вследствие тесных контактов с Римом, следует отметить применение цемента в качестве связующего раствора, обожжённого кирпича как нового материала, а также строительство терм и арок как новых типов архитектурных сооружений. Например, изображения арок присутствуют на монетах Рескупорида I (IOSPE I'2. 583) $[18$, с. 484 , илл. $137 ; 22$, с. $456-457$, рис. $232 ; 23$, с. 67-68, 70, 115].

Формы досуга, популярные в Римской империи, распространяются среди эллинов Северного Причерноморья: гладиаторские бои и бестиарии, посещение терм. Для новых типов представлений в Пантикапее был построен амфитеатр, а в Херсонесе при перестройке театра в I веке н.э. была увеличена высота барьера (IOSPE I². 483) $[13$, с. 72; 23, с 115]. На светильниках и некоторых других предметах быта первых веков н.э. встречаются изображения указанных развлечений [18, с. 508, илл. 157; 22, с. 477-478]. Гладиаторы и бестиарии представлены в росписи склепа 1841 года, а бестиарии и на деревянном саркофаге из Пантикапея [23, с. 116-117, рис. 38, 39, 39а].

О строительстве терм свидетельствуют как эпиграфические, так и археологические данные. В Херсонесе, Пантикапее и Кепах обнаружены остатки терм первых веков н.э., а надпись ІІ в. сообщает о том, что некий Деметрий построил термы на собственные средства (IOSPE I². 583) $[23$, c. 115].

Скульптурные портреты жителей Северного Причерноморья позволяют утверждать, что римская мода, в частности, на прически, проникала в регион. Например, в портрете бородатого мужчины из Керчи очень точно передана прическа «в виде прямых прядей волос, спускающихся на лоб и расходящихся в стороны посередине», типичная для времени Траяна, которая позволила исследователям датировать данный портрет началом ІІ в. н.э. [2, С. 106. № 65; 9, с. 297 слл.]. Подражает римской моде прическа Филократа на надгробии I в. н.э. из Херсонеса, а его голова в целом напоминает римский бюст эпохи Августа [9, с. 317, рис. 33; 23, с. 120, рис. 43]. Женщины северо-причерноморского региона также копировали модные прически римских матрон. Образцам для калькирования становились изображения жен принцепсов, различными путями попадавшие на периферию империи. Таким примером, возможно, является статуя из некрополя Илурата. Она была выполнена в привозной форме из местной глины, а оригиналом для формы послужил один из портретов Агриппины Старшей [4, с. 163-164]. Ещё одним образцом для копирования причесок могли послужить изображения на монетах, например, Ливии на сестерциях Рескупорида I [1, с. 100; 5, c. 201].

Авторитет римской культуры очень заметен в скульптурном портрете. Здесь можно выделить несколько аспектов заимствования и влияния. Так, на территории Боспорского царства появляются бронзовые конные статуи, образцами для которых были конные изображения римских императоров [5, с. 201, табл. XLVII-XLIX; 10, с. 136]. В стиле конной статуи Марка Аврелия выполнены скульптуры Рескупорида II, Савромата II, Рескупорида III [23, с. 119]. Второе новшество в скульптуре - портретное сходство, которое прослеживается на надгробных рельефах первых веков н.э., характерное скорее для римской, нежели для эллинской культуры $[2$, с. 106 , № $65 ; 9$, с. $137 ; 10$, с. $132-134 ; 11$, с. 356-359; 18, с. 495, илл. 147; 22, с. 458, 474, илл. 245; 23, с. 124]. Портреты римских и боспорских правителей на монетах Боспорского царства I-II вв. н.э. также весьма реалистичны [5, табл. XLVI, 9-12; табл. XLVII, 1, 2, 12].

Веяния римского портретного стиля обнаруживаются и в росписях склепов - яркость и красочность образов, реалистичность, продуманность деталей образов людей и их окружения (костюмы, вооружение, предметы быта). Данные тенденции часто сопоставляются исследователями с традиционно римскими стремлениями к пышности и роскоши в искусстве [6, с. 70-71].

В первые века новой эры в ономастиконе жителей городов Северного Причерноморья появляются римские имена, что связано с дарованием прав римского гражданства (IOSPE I². 93, 129, 202; КБН 44). Наибольший процент римских имен в рассматриваемый период отмечен исследователями в Херсонесе (20-25\%), несколько меньше - в Ольвии (около 17\%), менее всего - среди жителей Боспорского царства (около 5\%) [10, с. 107, 111,$113 ; 14$, с. $129 ; 19$, с. 19; 23, с. 98]. Надо иметь в виду, что указанные проценты означают долю римских имен лишь в сохранившихся надписях. И если мы посмотрим на эпиграфику Херсонеса (IOSPE I². 342-344, 350, 390, 403, 435, 460, 473, 540, 581, 689; НЭПХ І. 19, 43; II. 111, 112) и Ольвии (IOSPE I². 51, 80, 82, 85, 86, 91, 93, 95, 96, 99, 100, $102,105,106,111,116,128-132,134-138,140,142-144$, 148, 155-158, 162, 168, 169+177, 175, 176, 183, 685, 686; НО 80, 82, 86-88, 90, 170), дающую представление о просопонимике региона, то она чаще всего связана с должностными лицами, то есть отражает имена людей с достаточно высоким социальным статусом. Имена простых граждан представлены, в основном, на надгробиях, и среди них доля римских имен была, естественно, значительно ниже. Следует отметить, что в быту продолжали использовать греческие имена, а римские предназнача- 
лись для официальных случаев, например, при упоминании в почетных декретах [13, с. 58].

Римские «имена» получили и храмы: Кесарионы появились в Пантикапее, Фанагории и Гермонассе (IOSPE I'. 362) $[8$, с. $152 ; 23$, c. 117.

Собственно духовная сфера жизни населения причерноморских полисов незначительно подверглась римскому влиянию. И, вероятнее всего, коснулась лишь «верхушки» жителей. Возможно, в придворные круги Боспорского царства проникает стоицизм, отразившийся в мировоззрении автора энкомия из Пантикапея, который воспевает силу духа, милость к побежденным и доброту чествуемого [15, с. 67-68].

В религиозной жизни северо-причерноморского региона наиболее очевидным римским фактором стало распространение императорского культа, выражавшееся, в частности, в строительстве храмов и алтарей, статуй в честь правителей Рима и членов их семей, их обожествлении, отправлении культа (IOSPE І. 181; КБН 38, 41, 42, $48,52,877,891-983,1045-1047$ ) [20, с. 84-88; 23, с. 29, 119 , 131-132]. Судя по источникам, культ римских императоров раньше других государств региона появляется в Боспорском царстве (с правления Динамии - КБН 38, 1046), там же он получил наиболее разнообразные формы [20, с. 85-86; 23, с. 119, 131-132]. Однако, как и на территории Римской империи, в государствах Северного Причерноморья культ имел исключительно официальный характер.
Располагавшийся в регионе римский военный контингент почитал сугубо римских богов - Юпитера, Юноны, Минервы, Геркулеса, Меркурия [16, с. 53-65, 77; 19, с. 41-42, № 12; 22, с. 403-427]. Но какого-либо слияния, синкретизма этих божеств с местными культами не происходило, отправление их культов ограничилось местами дислокации римских гарнизонов.

Возможно, тесные контакты с Римской империей оказали косвенное воздействие на распространение некоторых эллинских культов. На Боспоре - Тюхе-Фортуны вследствие действий Калигулы по своему обожествлению [3, с. 163], в Херсонесе - Асклепия (из-за пребывания там римского военного контингента во второй половине I века) и Афродиты (в связи с представлениями о ней как родоначальнице римского народа) $[12$, с. 9].

Подводя итоги, следует отметить, что в эллинских государствах Северного Причерноморья в І-ІІ вВ. н.э. не приходится говорить о комплексной романизации, имевшей место во многих провинциях Римской Империи. При этом культурное воздействие Рима всё же прослеживается в монетном деле, архитектуре, скульптурном портрете и живописи, формах проведения досуга (посещении терм, гладиаторских игр и бестиариев), а в религиозной жизни - в появлении культа римских императоров. В наибольшей степени влияние отмечается В Боспорском царстве (кроме римских имен) и Херсонесе, которые и в политическом отношении наиболее тесно взаимодействовали с Римом.

\section{ЛИТЕРАТУРА}

1. Анохин В.А. Монетное дело Боспора. - Киев: Наукова думка, 1986. - 178 с.

2. Античная скульптура из собрания Государственного музея изобразительных искусств им. А.С. Пушкина. Под ред. Л.И. Акимовой. - М.: Изобразительное искусство, 1987. - 231 с..

3. Горончаровский В.А. Римско-Боспорский конфликт 40-х годов І В. н.э. // ВДИ. - 2003. - № 3. - С. 161-170.

4. Горончаровский В.А. Терракотовая статуя женского божества из раскопок некрополя Илурата: Афродита или Фортуна? // PONTIKA. Сборник научных статей. Под ред. Э.Д. Фролова. СПб., 2001. - С. 255-257.

5. Зограф А.Н. Античные монеты // МИА. - 1951. - № 16. - М.-Л., 1951. - 262 с.

6. Зубарь В.М. Северный Понт и Римская империя (середина І в. до н.э. - первая половина VI в. н.э.). - Киев: Ин-т археологии НАНУ, 1998. - 200 c.

7. арышковский П.О. Ольвия и Рим в І в.н.э. // Памятники римского и средневекового времени в Северо-Западном Причерноморье. Под ред. А.В. Гудковой. Киев: Наукова думка, 1982. С. 6-28.

8. Крыжицкий С.Д. К проблеме строительства в Северном Причерноморье храмов с нечетным количеством колонн по главному фасаду // ВДИ. - 2000. № 1. - С. 144-152.

9. Максимова М.И. Наливкина М.А. Скульптура // Античные города Северного Причерноморья. Отв. ред. В.Ф. Гайдукевич и М.И. Максимова. Т. І М. М.Л.: Изд-во АН СССР, 1955. С. 297-325.

10. Масленников А.А. Население Боспорского государства в первых веках н.э. - М.: Наука, 1990. - 232 с.

11. Медведев А.П. Новые открытия в Восточном некрополе Фанагории (2005 - 2007 гг.) // АМА. - 2010. - Вып. 14. - С. 350-368.

12. Мещеряков В.Ф. Религия и культы Херсонеса Таврического в I - IV вв. н.э. Автореф. дисс. . . . канд. ист. наук. - М., 1980. - 16 с.

13. Русяева А.С. Полисные традиции и влияния в культуре Херсонеса Таврического в римскую эпоху // Северное Причерноморье в эпоху античности и средневековья. Труды ГИМ. - Вып. 159. - 2006. - С. 56-75.

14. Савостина Е.А. Римские имена в ономастике Северного Причерноморья // СА. - 1977. - № 4. - С. 129-146. 
15. Сапрыкин С.Ю. Энкомий из Пантикапея и положение Боспорского царства в конце I - начале II в. н.э. // ВДИ. - 2005. - № 2. - С. $45-81$.

16. Сарновски Т., Савеля 0. Балаклава. Римская военная база и святилище Юпитера Долихена // Swiatowit. - Suppl. - Series A. Antiquity. - Vol. V. - Warszawa, 2000. $-276 c$

17. Смекалова Т.Н. Боспор в сфере влияния Римской империи (по данным о составе монетных сплавов) // ДБ. - 2001. - Т. 4. - С. $324-349$.

18. Соколов Г.И. Ольвия и Херсонес. Ионическое и дорическое искусство. - М.: Греко-латинский кабинет Ю.А. Шичалина, 1999. - 570 с.

19. Соломоник Э.И. Латинские надписи Херсонеса Таврического. Тексты. Перевод. Комментарий. - М.: Наука, 1983. - 94 с.

20. Тарасова Л.В. Культ римских императоров в городах Северного Причерноморья в I-ІІ вВ. н.э. // Научные труды КГПУ им. К.Э. Циолковского. Серия: Гуманитарные науки. - Калуга: Издательство КГПУ, 2008. - С. 84-88.

21. Фролова Н.А. Монетное дело Боспора (середина І В. до н.э. - середина IV в.н.э.). Часть І. - М., Эдиториал УРСС, 1997. - 448 с.

22. Херсонес Таврический в середине I В. до н.э. - VI в. н.э. Очерки истории и культуры. Под ред. В.М. Зубаря. - Харьков: Майдан, 2004. - 732 с.

23. Цветаева Г.А. Боспор и Рим. - М.: Наука, 1979. - 135 с.

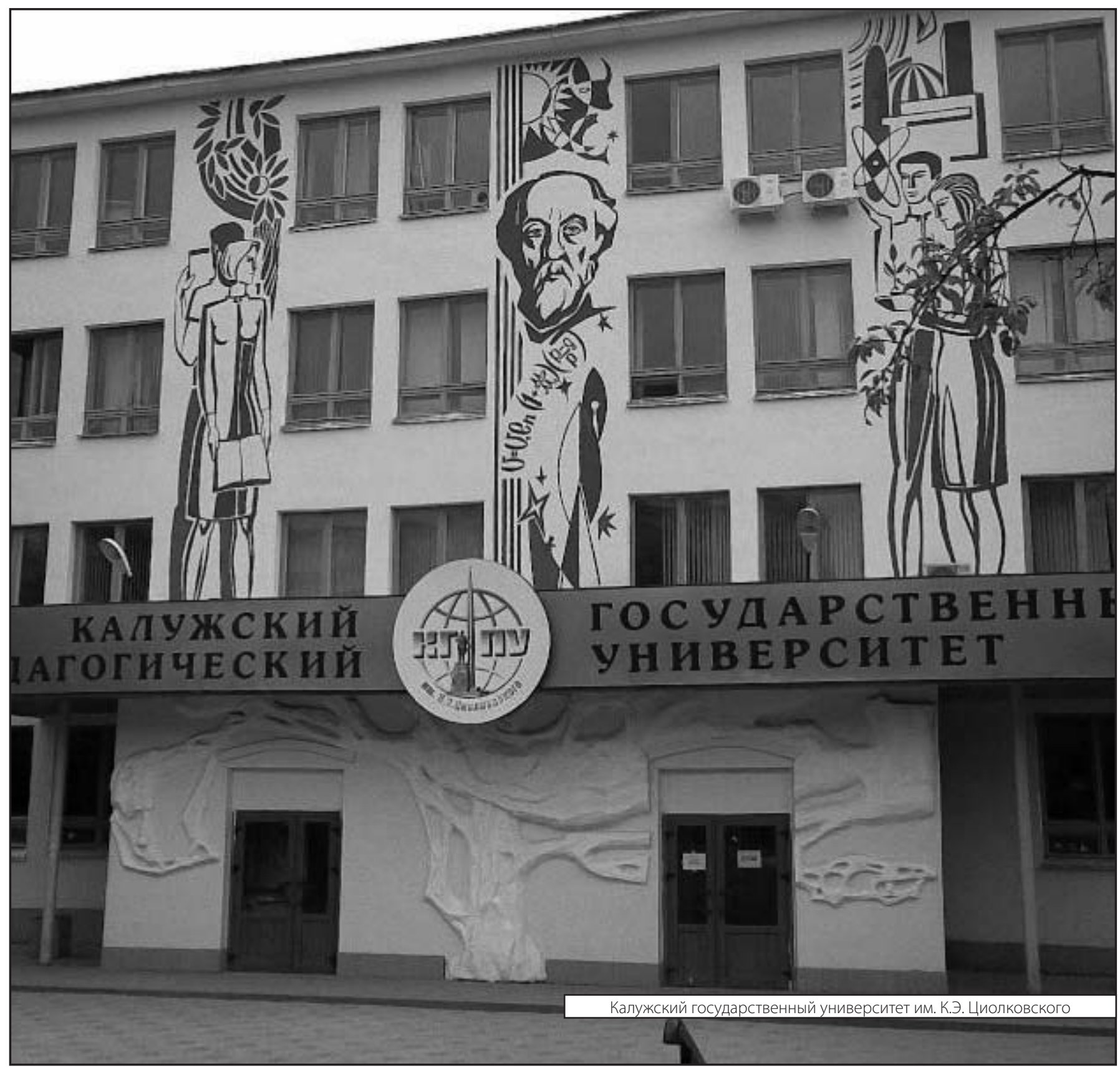

